\title{
Breastfeeding Self-Efficacy for Mothers at the Bulili Health Center, City Palu, Indonesia
}

\author{
Hemiyanty Hemiyanty*, Bertin Ayu Wandira, Novi Inriyanny Suwendro \\ Department of Public Health, Universitas Tadulako, Palu, Indonesia
}

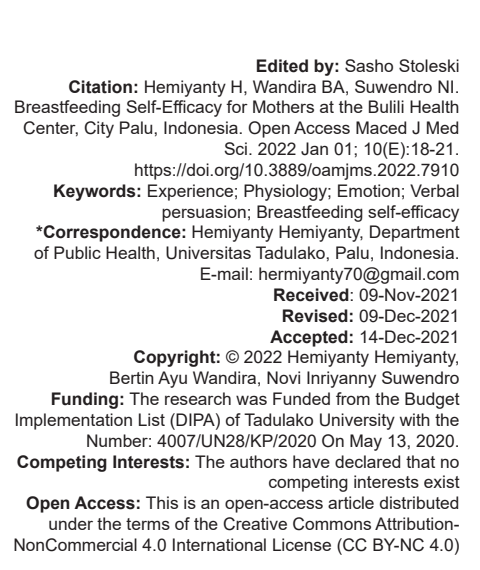

\section{Introduction}

Breast milk is the ideal food with a suitable composition for babies because it contains all the necessary nutrients and has immune substances that increase the baby's immunity from various diseases [1]. However, behind these extraordinary benefits, it turns out that the practice of exclusive breastfeeding is still low. The results of Riskesdas 2018 show that the coverage of exclusive breastfeeding in Indonesia is still around $37.3 \%$, very far from the Minimum Achievement Standard that the government has set, which is 80\% [2]. Then, data from the Palu City Health Office in 2019 showed that the percentage of exclusive breastfeeding was $57.8 \%$. Data from the Bulili Health Center showed a decrease in exclusive breastfeeding coverage, $37.17 \%$ in 2019 [3]. The average duration of breastfeeding worldwide is 20.5 months, and the average duration of exclusive breastfeeding in Indonesia is more than 3 months [4].

The low coverage of exclusive breastfeeding is associated with self-efficacy. Breastfeeding self-efficacy (BSE) is a mother's self-confidence or confidence in her ability to breastfeed her baby. Several studies have shown that mothers who are successful in exclusive breastfeeding have high levels of BSE [5]. Another study found that mothers with high BSE tend to continue breastfeeding for 4 months [6]. Mothers with low BSE have been shown to tend to use alternative techniques to breastfeed their babies when facing problems during breastfeeding [7].

The BSE of a mother can be modified through factors that affect self-efficacy. Based on factors related to BSE, a mother's confidence in her ability to breastfeed her baby can be influenced by previous breastfeeding experiences, observing breastfeeding behavior by others, or getting encouragement from others to breastfeed. In addition, his current physiological and affective state, including fatigue, stress, and anxiety, are important to note [8]. In Pradanie's research (2015), mothers who have had direct breastfeeding experience tend to be more confident to continue breastfeeding [9] Verbal persuasion about exclusive breastfeeding will make mothers want to breastfeed even more because they already know the various benefits and advantages. Stress management provides early knowledge about reducing stress and changing negative feelings so that 
mothers can make better judgments and interpretations of their abilities. A mother's BSE can be modified by influencing factors that affect self-efficacy [10].

\section{Method}

The design of this study was quantitative with a cross-sectional design. The study population was all mothers who had babies aged 6-12 months in the working area of the Bulili Public Health Center, Palu City, totaling about 447 people in 2021 . The sample size based on the Slovin formula was 82 people. The sampling technique in this study used purposive sampling. The sample was selected based on specific considerations with the following inclusion criteria: (1) Mothers who have babies aged 6-12 months; (2) Domiciled in the research location area; and (3) Willing to be a research informant.

The instrument used in this study was a questionnaire containing demographic data, breastfeeding experience data, observation of others, verbal persuasion, physical and emotional conditions, and BSE Scale-Short Form. Researchers have conducted validation and reliability tests on the Selfbreastfeeding experience, Other people experience, Verbal persuasive, Physiology and emotion, and BSE questionnaires and the results show that the results are valid and reliable. Data analysis using Fisher's Exact Test with a significant level of $p<0.05$.

\section{Results}

\section{Characteristics of respondents}

Table 1 shows that most respondents were aged $21-35$ years $(85.4 \%)$ and were dominated by

Table 1: Characteristics of respondents

\begin{tabular}{|c|c|c|}
\hline Characteristics & $\mathrm{n}$ & $\%$ \\
\hline \multicolumn{3}{|l|}{ Age (years old) } \\
\hline$<20$ & 6 & 7.3 \\
\hline $21-35$ & 70 & 85.4 \\
\hline$>35$ & 6 & 7.3 \\
\hline \multicolumn{3}{|l|}{ Religion } \\
\hline Hindu & 6 & 7.3 \\
\hline Islam & 58 & 70.7 \\
\hline Catholic & 1 & 1.2 \\
\hline Christian & 17 & 20.7 \\
\hline \multicolumn{3}{|l|}{ Occupation } \\
\hline Working & 16 & 19.5 \\
\hline Not working (housewive) & 66 & 80.5 \\
\hline \multicolumn{3}{|l|}{ Education } \\
\hline University & 26 & 31.7 \\
\hline Junior and Senior High school & 52 & 63.4 \\
\hline Primary school & 4 & 4.9 \\
\hline \multicolumn{3}{|l|}{ Number of children } \\
\hline 1-2 children & 68 & 82.9 \\
\hline 3-4 children & 12 & 14.6 \\
\hline$>4$ children & 2 & 2.4 \\
\hline \multicolumn{3}{|l|}{ Number of family members } \\
\hline $2-4$ persons & 51 & 62.2 \\
\hline 5-9 persons & 31 & 37.8 \\
\hline Total & 82 & 100.0 \\
\hline
\end{tabular}

Muslims (70.7\%). Then, respondents generally did not work or were housewive (80.5\%), and about $63.4 \%$ were finished high education (junior and senior high school). Averagely, their number of children was -2 people by $82.9 \%$, and the number of family members was 4 persons by $62.2 \%$.

\section{Research variables}

Table 2 shows that most respondents (62.9\%) had good breastfeeding experiences, and $17.1 \%$ were not. A total of $61.0 \%$ of the sample had experienced in the good category in observing breastfeeding activities carried out by other mothers, especially close friends and family, both directly and observing through recordings/videos (nursing advertisements/ videos. Verbal persuasion, in this case, the support provided by husband, family, friends, cadres, and health workers in the form of providing information, advice, advice, motivation, and attention that support mothers in exclusive breastfeeding were in a good category by $75.6 \%$. The physiological and emotional conditions of all respondents $(100 \%)$ were in a good category. About $90.2 \%$ of respondents were with BSE or beliefs that encourage breastfeeding mothers to carry out the breastfeeding process and fulfill exclusive breastfeeding for their babies.

Table 2: Distribution of independent and dependent variables

\begin{tabular}{lll}
\hline Variables & $\mathrm{n}$ & $\%$ \\
\hline Self - breastfeeding experience & & \\
$\quad$ Poor & 14 & 17.1 \\
$\quad$ Good & 68 & 82.9 \\
Other people experience & 32 & 39.0 \\
$\quad$ Poor & 50 & 61.0 \\
$\quad$ Good & & \\
Verbal persuasive & 20 & 24.4 \\
$\quad$ Poor & 62 & 75.6 \\
$\quad$ Good & 82 & 100.0 \\
Physiology and emotion & & \\
$\quad$ Good & 8 & 9.8 \\
BSE & 74 & 90.2 \\
$\quad$ Low & 82 & 100.0 \\
$\quad$ High & & \\
Total & & \\
\hline BSE: Breastfeeding self-efficacy. &
\end{tabular}

Table 3 shows that the respondent's breastfeeding experience did not significantly correlate with BSE with a $p=0.132(p<0.05)$. Then, the experience of other variables also showed no significant relationship with BSE with a $p=0.705$ ( $p<$ 0.05). Furthermore, the verbal persuasion variable also showed no significant relationship with BSE with $p=$ $0.396(p<0.05)$.

\section{Discussion}

This study indicates that the number of respondents with a good breastfeeding experience was $62.9 \%$. The breastfeeding experience is the most potent source of self-efficacy for changing behavior [11]. The experience of breastfeeding will have a different 
Table 3: Relationship between breastfeeding experience, experience of others, and verbal persuasion with BSE

\begin{tabular}{|c|c|c|c|c|}
\hline \multirow[t]{2}{*}{ Variables } & \multicolumn{2}{|l|}{ BSE } & \multirow[t]{2}{*}{ Total } & \multirow[t]{2}{*}{$\mathrm{p}$-value } \\
\hline & Low & High & & \\
\hline \multicolumn{5}{|c|}{ Self-breastfeeding experience } \\
\hline \multicolumn{5}{|c|}{ Poor } \\
\hline $\mathrm{n}$ & 3 & 11 & 14 & \multirow[t]{5}{*}{0.132} \\
\hline$\%$ & 21.4 & 78.6 & 17.1 & \\
\hline \multicolumn{4}{|l|}{ Good } & \\
\hline $\mathrm{n}$ & 5 & 63 & 68 & \\
\hline$\%$ & 7.4 & 92.6 & 82.9 & \\
\hline \multirow{2}{*}{\multicolumn{5}{|c|}{ Other people breastfeeding experience }} \\
\hline Poor & & & & \multirow{3}{*}{0.705} \\
\hline $\mathrm{n}$ & 4 & 28 & 32 & \\
\hline$\%$ & 12.5 & 87.5 & 39.0 & \\
\hline \multicolumn{5}{|l|}{ Good } \\
\hline $\mathrm{n}$ & 4 & 46 & 50 & \\
\hline$\%$ & 8.0 & 92.0 & 61.0 & \\
\hline \multicolumn{5}{|c|}{ Verbal persuasion } \\
\hline \multicolumn{5}{|c|}{ Poor } \\
\hline $\mathrm{n}$ & 3 & 17 & 20 & \multirow[t]{2}{*}{0.396} \\
\hline$\%$ & 15.0 & 85.0 & 24.4 & \\
\hline \multicolumn{5}{|l|}{ Good } \\
\hline $\mathrm{n}$ & 5 & 57 & 62 & \\
\hline$\%$ & 8.1 & 91.9 & 75.6 & \\
\hline \multicolumn{5}{|l|}{ Total } \\
\hline $\mathrm{n}$ & 8 & 74 & 82 & \\
\hline$\%$ & 9.8 & 90.2 & 100 & \\
\hline
\end{tabular}

impact on self-confidence, depending on the process of achievement. It may increase the mother's confidence to create a strong desire to breastfeed her baby [12]. Mothers with primiparous status did not express their milk more smoothly than multiparas. Mothers were more experience in breastfeeding, given their breast milk directly to babies [13]. Other studies have shown that mothers who do not intend to give exclusive breastfeeding due to their previous experience of not breastfeeding, working mothers, and mothers believe that their breast milk cannot make babies full, so they need additional formula milk [14]. A study showed that several phenomena emerged from the category linkage analysis. Those showed the experience of exclusive breastfeeding for working mothers who practice exclusive breastfeeding. The breastfeeding activity was influenced by the mother's perception and understanding obtained from knowledge for working mothers. The knowledge can be obtained from health workers or other sources of information such as mass media, where information is obtained either directly or indirectly, from integrated health service centers (Posyandu), mass media (newspapers, others). In addition, the existence of culture and myths that support exclusive breastfeeding and vice versa also affect the practice of breastfeeding mothers [15].

Mothers who have friends or family members who are successful in breastfeeding will prefer and try to breastfeed. In contrast, mothers who have never seen the process of breastfeeding their babies will feel embarrassed and awkward to breastfeed. Self-efficacy is influenced by personal experiences that have been passed in the form of success and failure. A grandmother who has experience when caring for her child can give exclusive breastfeeding will increase self-efficacy in assisting her child (the mother who is breastfeeding) so that her child gives exclusive breastfeeding with more than one child and the age of grandchildren is more than 6 months will make a grandmother have good selfefficacy. In addition, the experience of self-efficacy can be increased through verbal persuasion that can be done repeatedly [16]. The study results by Agunbiade (2012) in West Nigeria stated that the grandmother or mother-in-law plays a role in producing children's health, namely the culture of breastfeeding [17]. Personal experiences and networks of support influence the forms and quality of breastfeeding practices. Largely, these factors pressure breastfeeding mothers, thereby making their experience pleasurable or painful within time and space [18].

This study indicates that verbal persuasion was included in the good category of $75.6 \%$. Persuasion can be in the form of advice, attention, motivation, advice, support, and the provision of information or teaching. This is obtained from the closest people to breastfeeding mothers: husbands, mother-in-law/birthdays, friends, posyandu cadres, and health workers. Tradition factors or habits in the family can also influence the mother's desire to breastfeed her child because husband and family are the main sources of persuasion for breastfeeding mothers.

Then, the physiological and emotional conditions of the respondents showed a good category for $100 \%$. A good condition is the absence of fatigue, pressure, and stress that makes the mother not want to breastfeed her baby. Mother always feels happy and satisfied after breastfeeding her baby. Another study showed that $70.9 \%$ of respondents experienced a good condition in both physical and emotional aspects [19].

Self-efficacy in breastfeeding mothers is very important. Mothers with high self-efficacy breastfeed longer than those with low self-efficacy, and there is a positive correlation between self-efficacy on the first postpartum day and breastfeeding duration at 2 months postpartum [20]. BSE in this study was in a good category, namely $90.2 \%$. However, based on the results of this study, breastfeeding experience factors, other people's experiences, physiological and emotional conditions, and verbal persuasion did not have a significant relationship to BSE of mothers and babies in the Work Area of the Bulili Health Center, Palu City. This means that other variables affect the BSE of mothers and babies in the Work Area of the Bulili Public Health Center, Palu City, which was not discussed in this study. Breastfeeding efficacy is significantly related to breastfeeding duration, and exclusive breastfeeding duration could increase the BSE of mothers [21]. The results described indicate that the assessment of breastfeeding duration may be helpful to gauge the maternal breastfeeding efficacy. To increase the rates of short duration and exclusivity levels of breastfeeding, it is suggested that health professionals consistently evaluate high-risk mothers who may stop early and recognize the BSE levels of mothers [21]

The limitation of the study is that data collection was carried out in the COVID-19 pandemic situation so 
that the interaction between the data collection team and respondents was lacking with reasons to maintain distance in order to comply with health protocols so that there was a tendency for respondents to be unfocused and potentially cause inaccurate data. However, the research team still strives to produce accurate data by maintaining good relationships with respondents.

\section{Conclusion}

BSE is high and very supportive for the implementation of exclusive breastfeeding. Despite other contributing factors such as the breastfeeding experience, other people's experiences, physiological and emotional conditions, and verbal persuasion do not significantly correlate to mothers' and babies' BSE in the Bulili Health Center Work Area, Palu City.

\section{References}

1. Ballard O, Morrow AL. Human milk composition: Nutrients and bioactive factors. Pediatr Clin North Am. 2013;60(1):49-74. https://doi.org/10.1016/j.pcl.2012.10.002 PMid:23178060

2. Kemenkes RI. Main Results of Riskesdas 2018. Jakarta, Indonesia: Kementerian Kesehatan Rl; 2018.

3. Dinas Kesehatan Kota Palu. Health Profile Palu City 2019. Palu: Dinas Kesehatan Kota Palu; 2019.

4. Awaliyah SN, Rachmawati IN, Rahmah H. Breastfeeding selfefficacy as a dominant factor affecting maternal breastfeeding satisfaction. BMC Nurs. 2019;18(1):30.

5. Loke AY, Chan LK. Maternal breastfeeding self-efficacy and the breastfeeding behaviors of newborns in the practice of exclusive breastfeeding. J Obstet Gynecol Neonatal Nurs. 2013;42(6):672-84. https://doi.org/10.1111/1552-6909.12250 PMid:24128113

6. BlythR,CreedyDK, DennisCL,MoyleW,PrattJ,DeVriesSM. Effect of maternal confidence on breastfeeding duration: An application of breastfeeding self-efficacy theory. Birth. 2002;29(4):278-84 . https://doi.org/10.1046/j.1523-536x.2002.00202.x PMid: 12484390

7. Keemer F. Breastfeeding Self-efficacy and Alternative Techniques to Overcome Maternal or Infant Breastfeeding Challenges: A Retrospective Descriptive Study. Queensland: Queensland University of Technology; 2011.
8. Dennis $\mathrm{CL}$, Faux S. Development and psychometric testing of the breastfeeding self-efficacy scale. Res Nurs Health. 1999;22(5):399-409. https://doi.org/10.1002/ (sici)1098-240x(199910)22:5<399:aid-nur6>3.0.co;2-4 PMid:10520192

9. Pradanie R. Breastfeeding self-efficacy and effective breastfeeding on postpartum mother. Ners. 2015;10(1):20-9.

10. Nursan C, Dilek K, Sevin A. Breastfeeding self-efficacy of mothers and the affecting factors. Aquichan. 2014;14(3):327-35.

11. Otsuka K, Taguri M, Dennis CL, Wakutani K, Awano M, Yamaguchi T, et al. Effectiveness of a breastfeeding self-efficacy intervention: Do hospital practices make a difference? Matern Child Health J. 2014;18(1):296-306. https://doi.org/10.1007/ s10995-013-1265-2

PMid:23592322

12. Leurer MD, Misskey E. The psychosocial and emotional experience of breastfeeding: Reflections of mothers. Glob Qual Nurs Res. 2015;2:2333393615611654. https://doi. org/10.1177/2333393615611654 PMid:28462320

13. Deafira A, Wilar R, Kaunang ED. Factors affecting the success of breastfeeding infants treated at several health facilities in manado city. J e-Clin. 2017;5(2):228-34.

14. Yusrina A, Devy SR. Influencing factors of the intentions mothers breastfeeding exclusively in Kelurahan Magersari, Sidoarjo. J Promkes. 2016;4(1):11-21

15. Rejeki S. Phenomenology study: Exclusive breastfeeding experience of working mothers in kendal region, central java. Media Ners. 2008;2(1):1-13.

16. Wibowo H, Probowati R, Muhith A, Savitri M, Khamida grandmother's self efficacy in exclusive breastfeeding for breastfeeding mothers aged 1-6 months with a health promotion model approach. J Health sci. 2019;12(2):1-14.

17. Agunbiade OM, Ogunleye OV. Constraints to exclusive breastfeeding practice among breastfeeding mothers in Southwest Nigeria: Implications for scaling up. Int Breastfeed J. 2012;7(1):5.

18. Zoller HM, Dutta MJ, editors. Emerging perspectives in health communication: Meaning, culture, and power. In: Supporting Breastfeeding (?): Nursing Mothers' Resistance to and Accommodation of Medical and Social Discourses. Ch. 3. New York: Routledge, Taylor and Francis Group; 2008. p. 486.

19. Agustin ED, Yunitasari E, Fauziningtyas R. Analisis FaktorFaktor yang Berhubungan dengan Breastfeeding Self-Efficacy di Puskesmas Sreseh Kabupaten Sampang. Surabaya: Universitas Airlangga; 2018.

20. Zakiah, Rasyad AS, Sujatno HR. Self-efficacy and duration of breastfeeding only for 2 months postpartum. Gaster. 2012;9(2):7-16.

21. Pakseresht S, Pourshaban F, khalesi ZB. Comparing materna breastfeeding self-efficacy during first week and sixth week postpartum. Electron Physician. 2017:9(2):3751-5. https://doi. org/10.19082/3751

PMid:28465802 